drückt werden. Die Schutzwirkung greift offensichtlich schon in einen sehr frühen Prozess der Aktivierung ein. So zeigte sich, dass beide Thiol-Antioxidanzien die Bindung von 2,4,6-Trinitrochlorbenzol an Proteinstrukturen in Monozyten und reifen dendritischen Zellen blockieren. Die nicht Thiolgruppen-haltigen Antioxidanzien Ascorbinsäure und alpha-Tocopherol konnten dagegen die Phosphorylierung und damit auch die Aktivierung der Monozyten nicht verhindern.

Fazit: Thiolhaltige Antioxidanzien verhindern die Aktivierung von CD14-Zellen durch stark kontaktsensibilisierende Substanzen wahrscheinlich durch Bindung an bestimmte zelluläre Strukturen. Ob sich SH-Grup-
pen-Verbindungen wie N-Acetylcystein tatsächlich für die Prävention eines allergischen Kontaktekzems eignen, müssen nun In-vivo-Studien zeigen.

Bruchhausen S et al. Thiol antioxidants block the activiation of antigenpresenting cells by contact sensitizers. J Invest Dermatol 2003; 121: 1039-44

\title{
Soforttypreaktion gegen Persulfat manchmal IgE-vermittelt
}

\section{Persulfatsalze finden als starke Oxidationsmittel unter anderem in Blondierungen und Zahnprothesenreinigern Verwendung. Vor allem bei Friseuren rufen sie allergische Reaktionen wie Kontakturtikaria, allergische und irritative Kontaktdermatitiden oder Asthma hervor. Eine Studie untersuchte diese Reaktionen genauer.}

F innische Allergologen dokumentierten über einen längeren Zeitraum die Daten von 138 konsekutiven Patienten mit Verdacht auf eine allergische Kontaktdermatitis gegen Haarpflegeprodukte. Durch verschiedene Tests wollten sie einer möglichen Sensibilisierung der Probanden gegen Persulfat auf die Spur zu kommen. Zunächst erfolgten Pricktestungen mit frisch bereiteten 2\%igen Ammonium- und KaliumpersulfatLösungen, die innerhalb von 30 Minuten appliziert wurden. Bei Patienten mit einer positiven Reaktion wurden dann im offenen Applikationstest ebenfalls frisch bereitete 5\%ige Lösungen auf den Unterarm aufgebracht und leicht in die Haut eingerieben. 20 gesunde Probanden dienten für die Hauttestungen als Kontrolle. Zusätzlich führte man bei positivem Pricktest Immunospot und RAST zum Nachweis von Persulfat-spezifischen IgE-Antikörpern durch.

Insgesamt sieben Patienten (5\%, alle übten den Friseurberuf aus) hatten eine positive Prickreaktion gegen mindestens eines der
Persulfatsalze. Klinisch waren bei diesen Patienten Hautsymptome wie Urtikaria, Angioödem oder Ekzeme bei

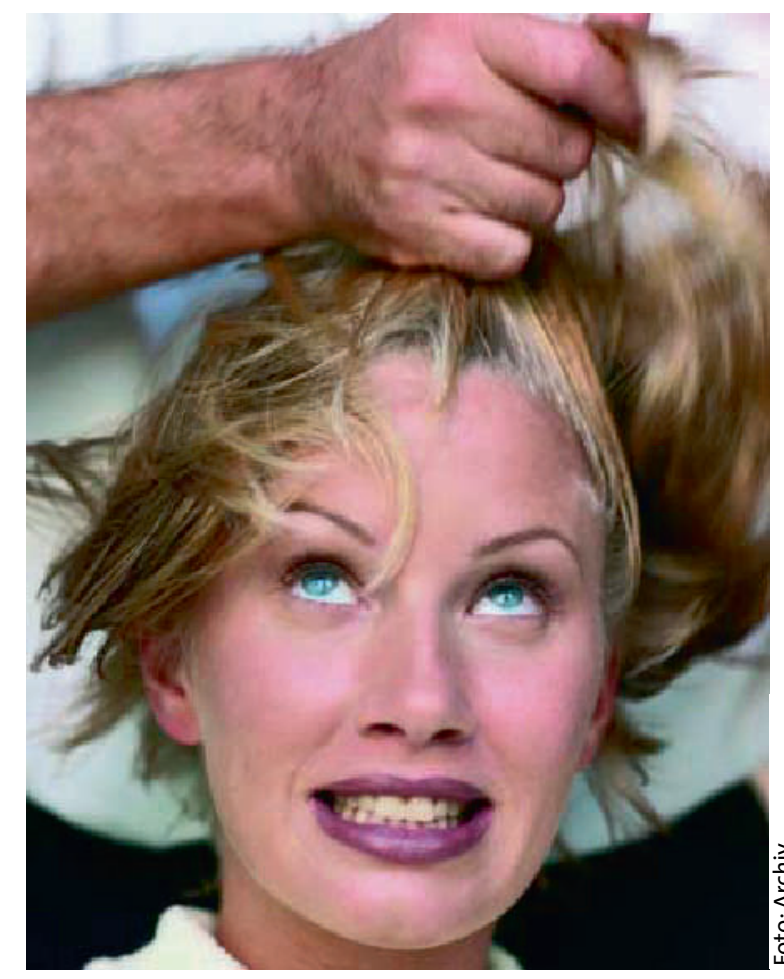

Blondes Gift? Die in Haarbleichmitteln enthaltenen Persulfatsalze sind ein typischer Auslöser von Kontaktallergie bei Friseuren.
Kontakt mit Haarbleichmitteln bekannt, vier von ihnen berichteten zusätzlich über eine Rhinitis, zwei hatten außerdem eine Konjunktivitis. Im offenen Hauttest, durchgeführt bei vier Patienten, zeigten drei eine Positivreaktion.

Mit fünf Patientenseren wurden bis zu 3 Jahre nach dem positiven Pricktest In-vitro-Untersuchungen durchgeführt. Dabei ließ sich in den Proben zweier Patienten im Immunospottest spezifisch an Human-Serumalbumin (HSA) konjugiertes Ammonium- und Kaliumpersulfat bindendes IgE nachweisen. Das Serum eines dieser Patienten war auch im RAST positiv gegenüber dem Ammoniumpersulfat-HSAKonjugat. Möglicherweise wäre die Rate an positiven In-vitroTests höher gewesen, wenn man sie alle unmittelbar nach dem Pricktest durchgeführt hätte. So hatten in der Zwischenzeit einige Patienten ihren Beruf gewechselt oder sich zumindest gegen Persulfat durch Handschuhe geschützt.

Fazit: Persulfatsalze führen häufiger zu einer Soforttypreaktion als zu einer Spättypreaktion. Die Sensibilisierung kann mit einer frisch bereiteten Ammoniumpersulfatlösung im Pricktest nachgewiesen werden. In einigen Fällen liegt eine IgE-vermittelte Reaktion mit positivem RAST vor.

$b k$

Aalto-Korte $\mathrm{K}$ et al. Specific immunglobulin $\mathrm{E}$ in patients with immediate persulfate hypersensitivity. Contact Dermatitis 2003; 49: 22-25 